\title{
Personality traits and coping styles in women with Mayer-Rokitansky-Küster-Hauser syndrome
}

Kamilla Bargiel-Matusiewicz ${ }^{1}$, Aleksandra Kroemeke²

${ }^{1}$ Faculty of Psychology, University of Warsaw, Warsaw, Poland

${ }^{2}$ Department of Psychology, University of Social Sciences and Humanities, Warsaw, Poland

Submitted: 2 February 2014

Accepted: 20 April 2014

Arch Med Sci 2015; 11, 6: 1244-1249

DOI: $10.5114 /$ aoms.2015.56350

Copyright @ 2015 Termedia \& Banach

\section{Abstract}

Introduction: The purpose of the study was to determine whether women with Mayer-Rokitansky-Küster-Hauser (MRKH) syndrome differ from healthy women as regards personality traits and coping styles.

Material and methods: Personality (the Big Five) and coping styles (problem-, emotion- and avoidance-focused coping) were analyzed in a group of 46 women with MRKH syndrome (age: $M=23.48 ; S D=4.88$ ), and in a group of 44 healthy women (age: $M=25.95 ; S D=5.24$ ), based on Polish versions of the NEO-FFI and CISS inventories.

Results: Results of analysis of covariance (ANCOVA, age, education and having a partner controlled) revealed significant differences in neuroticism level (F1.86 $=7.01, p<0.01)$ and problem ( $\mathrm{F} 1.86=7.88, p<0.01)$ and emotion-focused (F1.86 $=4.98, p<0.05)$ coping styles. Differences in the level of neuroticism and instrumental coping was also revealed in analyses which took into account the time for which individuals have been aware of their illness: in women who have been aware of the MRKH diagnosis for more than 6 years, the level of neuroticism was higher $(\mathrm{F} 1.85=3.97, p<0.05)$ and the problem-focused coping style was at a lower level $(\mathrm{F} 1.85=3.93, p<0.05)$ than in healthy women. Conclusions: The results obtained make it possible to identify basic psychological problems related to MRKH syndrome, and to formulate proposals on psychological interventions addressed to this group of women. This study showed that with time negative psychological consequences become more severe, and thus those women should be provided with specialist help from the moment the diagnosis is made.

Key words: Mayer-Rokitansky-Küster-Hauser syndrome, personality, coping style.

\section{Introduction}

This paper focuses on selected mental functioning disorders in women with Mayer-Rokitansky-Küster-Hauser (MRKH) syndrome. The MRKH syndrome is a congenital absence of the uterus and vagina, or their serious malformation, which in consequence results in infertility. In most cases ovaries are developed normally and their usual functions are maintained. Therefore no hormonal imbalance is observed, and tertiary sex features may develop normally in girls with MRKH syndrome [1]. The most common first clinical symptom of MRKH syndrome is the primary lack of menstruation; therefore the syndrome is diagnosed relatively late, most often in patients aged around 16 [2].

\author{
Corresponding author: \\ Aleksandra Kroemeke PhD \\ Department of Psychology \\ University of Social \\ Sciences and Humanities \\ 19/31 Chodakowska St \\ 03-815 Warsaw, Poland \\ Phone: +48 225179824 \\ E-mail: \\ akroemeke@swps.edu.pl
}


Difficulties in sexual activity, infertility and also the related long-term treatment are a considerable emotional burden. Furthermore, taking into account the fact that in most cases this information is conveyed in the puberty period, it may have a considerable impact on psychosocial development of a young woman [3]. According to Bishop [4], receiving the diagnosis is an event that may be analyzed in terms of a psychological crisis i.e., a sudden situation characterized by changes that are so serious, negative and different from current experiences that the commonly used coping strategies prove to be insufficient. Many negative emotions such as fear, anger or sense of guilt emerge then [5]. According to the interactional coping model, coping with a crisis situation depends on a number of factors including permanent features of the subject such as personality traits or coping skills, i.e. coping style [6].

The aim of the study was to compare women with MRKH syndrome (classic type) with healthy female controls as regards intensification of personality traits included in the Big Five Theory (agreeableness, extraversion, neuroticism, conscientiousness and openness to experience) [7], and coping style (problem-, emotion- or avoidance-focused) [6]. In this context, the level of neuroticism is of crucial importance since this dimension defines vulnerability to experiencing negative emotions in response to psychological stress. Components of neuroticism include fear, aggressive hostility, depressiveness, impulsiveness, oversensitivity and excessive self-criticism [7, 8]. The results of the previous study suggest that infertile women score higher on all scales measuring fear, and furthermore they are more emotionally unsteady [3, 9]. Extraversion, on the other hand, defines the level of sociability, activity and tendency to respond with positive emotions $[7,8]$. Positive valuation of life events, including curiosity and tolerance for novelties, results in openness to experience. Agreeableness describes an individual's attitude towards others (trust, altruism, cooperative behavior), while conscientiousness refers to their attitude towards tasks (the degree of involvement and organization) [7, 8]. Results of studies on health problems other than infertility show that extraversion and openness to experience are considerably lower in sick than in healthy women [10].

As for coping skills, it has been found that the avoidance- and emotion-focused coping style prevails in the group of infertile women [3, 11, 12]. Studies on other conditions also suggest that coping styles may be related to an illness. For instance, it has been shown that epileptics use different coping styles than healthy individuals [13], whereas in a group of patients suffering from chronic fatigue syndrome there are differences in coping styles, depending on how long they have suffered from the condition [14].

The study also shows that women who have struggled with the problem of infertility for 2 or 3 years have more symptoms of depression than women who have been aware of their infertility for up to one year or for more than 6 years [11]. This phenomenon may be explained by the activation of a number of defense mechanisms (denial, intellectualization, rationalization), in response to the diagnosis, and complete adaptation to the illness (acceptance of the fact of being infertile), after about 6 years following diagnosis [cf. 11]. In view of the above, the study presented in this paper also took into account the time factor.

\section{Material and methods}

\section{Sample and procedure}

The study included 46 women with MRKH syndrome aged 18 to $37(M=23.48 ; S D=4.88)$. The vast majority of the respondents had secondary or university education (91.3\%). The women represented classic MRKH syndrome [15]. They were advised to do stretching exercises, and some of them have undergone surgery. All the women had sexual experiences. The most important problem for them was infertility. Thirty-seven percent had a partner. Average time since the participants were diagnosed with the syndrome was 6.24 years $(S D=4.34)$, and ranged from 1 to 17 years. Female controls included 44 women without symptoms of somatic disorders, aged 18 to $37(M=25.95$; $S D=5.24)$, with secondary or university education ( $41 \%$ and $59 \%$, respectively). Female controls turned out to be significantly older than the clinical group $(t[88]=-2.321, p<0.05)$.

The study was conducted individually. The criterion of selection was the period of early adulthood as this is usually the period of life when stable relationships are established and families started, which may be an additional source of stress for ill women. The authors obtained approval from the Ethics Committee at the University of Warsaw to perform the study.

\section{Measures}

Personality was measured based on the NEO Five-Factor Inventory (NEO-FFI) by Costa and McCrae [16] (Polish adaptation: Zawadzki, Strelau, Szczepaniak \& Śliwińska [8]), which makes it possible to measure neuroticism, extraversion, openness to experience, agreeableness and conscientiousness. Respondents were asked to take a stance on each statement using the 5-point Likert scale. The style of coping with stress was assessed based on Endler and Parker's Coping Inventory for Stressful Situations (CISS) [17] (Polish 
adaptation: Strelau, Wrześniewski, Jaworowska and Szczepaniak [18]), which makes it possible to assess the problem-, emotion- and avoidance-focused coping styles. The latter was divided into distraction seeking and social diversion. Respondents were asked to express their attitude towards statements concerning a tendency to take remedial action in difficult situations, based on the 5-point Likert scale.

\section{Statistical analysis}

A general test of differences between average values was conducted to compare the group of women with MRKH syndrome with healthy women with respect to personality variables and coping ability. Demographic variables including age, educational level and having a partner were controlled in all analyses and the analyses were conducted based on one-way analysis of covariance (ANCOVA), SPSS 20.

\section{Results}

First, women with MRKH syndrome were compared to healthy women with respect to personality dimensions and coping styles. Table I presents descriptive statistics for variables analyzed in both groups of women. Analyses of average values (with age, education and having a partner as covariates) showed significant differences: when compared to the female controls, women with MRKH syndrome scored higher in neuroticism, and had a stronger tendency to use emotion-focused coping but scored lower in using problem-focused coping (Table I).
In view of the reported influence of the time for which individuals have been aware of the disease on the permanent personality variables, differences were also expected with respect to personality traits and coping styles among women with MRKH syndrome who have known the diagnosis for a longer or a shorter period of time. Due to the frequency distribution of time related to syndrome awareness (only 6 women who have known the diagnosis for the period of up to 1 year i.e., $13 \%$ of the total sample), the study group was divided into two subgroups with a cut-off point of 6 years, and in consequence only the hypothesis assuming that adaptation to the fact of being infertile takes place 6 years from receiving the diagnosis was verified. Thus, one-way covariance analysis (ANCOVA) was conducted with post hoc comparisons in order to compare women with MRKH syndrome who have known the diagnosis for 6 years or less, women who have known the diagnosis for more than 6 years, and healthy women with respect to personality traits and coping styles (cf. Table II). The results showed significant differences in neuroticism and problem-focused coping style between the group of women who have been aware of their illness for more than 6 years and the female controls. Analogically to earlier results, women with MRKH syndrome who have been aware of the illness for $>6$ years scored higher in neuroticism $(p<0.05)$, and lower in problem-focused coping style $(p<0.05)$, than healthy women. No significant differences were observed between women who have been aware of the diagnosis for a shorter period of time (up to 6 years) or longer (more than 6 years), or between the female con-

Table I. Descriptive statistics and ANCOVA results in a group of healthy women and those with MRKH syndrome

\begin{tabular}{|c|c|c|c|c|c|c|}
\hline \multirow[t]{2}{*}{ Variables } & \multicolumn{2}{|c|}{$\begin{array}{l}\text { Women with MRKH syndrome } \\
\qquad N=46\end{array}$} & \multicolumn{2}{|c|}{$\begin{array}{l}\text { Healthy women } \\
\qquad N=44\end{array}$} & \multirow[t]{2}{*}{$F(1,86)$} & \multirow[t]{2}{*}{ Partial $\eta$} \\
\hline & $M$ & SD & $M$ & SD & & \\
\hline A & 30.93 & 5.36 & 30.52 & 5.46 & 0.65 & - \\
\hline $\mathrm{E}$ & 35.73 & 6.60 & 38.00 & 6.65 & 2.24 & - \\
\hline$N$ & 31.24 & 9.96 & 26.48 & 5.80 & $7.01^{\star *}$ & 0.08 \\
\hline C & 37.16 & 4.64 & 36.89 & 5.79 & 0.10 & - \\
\hline 0 & 30.75 & 5.27 & 30.23 & 5.36 & 0.03 & - \\
\hline Problem & 43.11 & 4.34 & 45.43 & 3.16 & $7.88^{\star *}$ & 0.09 \\
\hline Emotion & 55.22 & 8.37 & 51.20 & 5.33 & $4.98^{*}$ & 0.05 \\
\hline Avoidance & 32.22 & 4.74 & 33.05 & 4.16 & 0.80 & - \\
\hline Distraction & 13.65 & 3.18 & 14.66 & 2.81 & 1.46 & - \\
\hline Social Div. & 12.67 & 4.51 & 12.55 & 3.72 & 0.68 & - \\
\hline
\end{tabular}

$A$-Agreeableness, $E$-extraversion, $N$-neuroticism, $C$-conscientiousness, $O$-openness to experience, Problem-problem-focused coping style, Emotion - emotion-focused coping style, Avoidance - avoidance-focused coping style, Social Div. - social diversion. The covariates were statistically related only to conscientiousness: age, $F(1.86)=7.47 ; p<0.01$; education, $F(1.86)=9.68 ; p<0.01$; having a partner, $F(1.86)=5.26 ; p<0.05$. No interaction effects were found. ${ }^{*} p<0.05 ;{ }^{* *} p<0.01$. 
Table II. Results of one-way covariance analysis (ANCOVA)

\begin{tabular}{|lccccccccc|}
\hline Variables & $\begin{array}{c}\text { Women with MRKH } \\
\text { syndrome } \leq 6\end{array}$ & \multicolumn{2}{c}{$\begin{array}{c}\text { Women with MRKH } \\
\text { syndrome }>6 \\
N=23\end{array}$} & \multicolumn{2}{c}{$\begin{array}{c}\text { Healthy women } \\
N=44\end{array}$} & & $F(2.85)$ & Partial $\eta^{2}$ \\
& $\mathbf{M}$ & SD & $\mathbf{M}$ & SD & $\mathbf{M}$ & SD & & \\
\hline A & 30.41 & 5.98 & 30.46 & 4.74 & 30.52 & 5.46 & 2.48 & - \\
\hline E & 36.80 & 7.75 & 34.84 & 6.43 & 38.00 & 6.65 & 2.54 & - \\
\hline N & 30.39 & 10.35 & 32.10 & 9.70 & 26.48 & 5.80 & $3.97^{*}$ & 0.09 \\
\hline C & 37.34 & 5.18 & 36.96 & 4.14 & 36.88 & 5.79 & 0.24 & - \\
\hline O & 31.67 & 4.81 & 29.83 & 5.66 & 30.23 & 5.36 & 0.23 & - \\
\hline Problem & 43.29 & 4.89 & 42.95 & 3.82 & 45.43 & 3.16 & $3.93^{*}$ & 0.09 \\
\hline Emotion & 55.78 & 8.91 & 54.65 & 7.96 & 51.20 & 5.33 & 2.52 & - \\
\hline Avoidance & 33.10 & 5.21 & 31.35 & 4.15 & 33.04 & 4.16 & 1.51 & - \\
\hline Distraction & 13.87 & 3.41 & 13.43 & 2.98 & 14.66 & 2.81 & 0.40 & - \\
\hline Social Div. & 13.65 & 4.60 & 11.69 & 4.30 & 12.55 & 3.72 & 1.86 & - \\
\hline
\end{tabular}

A-Agreeableness, $E$-extraversion, $N$-neuroticism, $C$-conscientiousness, $O$-openness to experience, Problem-problem-focused coping style, Emotion - emotion-focused coping style, Avoidance - avoidance-focused coping style, Social Div. - social diversion. Significant differences between pairs of variables are shown in bold font. The covariates were statistically related to conscientiousness: age, $F(1.86)=$ 5.13; $p<0.05$; education, $F(1.86)=9.60 ; p<0.01$; having a partner, $F(1.86)=5.96 ; p<0.05$, and extraversion: education, $F(1.86)=4.40$; $p<0.05$. No interaction effects were found. * $p<0.05$.

trols and women with MRKH syndrome aware of the diagnosis for $\leq 6$ years.

\section{Discussion}

This report presents a comparison of a group of women with MRKH syndrome with healthy women with respect to personality dimensions and coping styles. The results show that women with MRKH syndrome achieved higher scores in neuroticism and emotion-focused coping and lower scores in problem-focused coping than healthy females.

Higher neuroticism in the group of ill women may indicate that they experience negative emotions (see e.g., a study among cancer patients: higher emotional reactivity - a temperament trait similar to neuroticism - was associated with greater intensity of symptoms of post-traumatic stress disorders [19]; It is worth noting that neuroticism and emotional reactivity have similar functional properties). This in turn may lead to isolation from others, and a constant focus on oneself, one's condition and negative experiences related thereto. According to the concept, neuroticism reflects emotional instability but it defines a certain permanent feature shaped since childhood. Therefore it cannot be ruled out that the women with MRKH syndrome covered by the study have always been characterized by the feature in question. Unfortunately the cross-sectional character of the study does not make it possible to define the cause and effect relations between the illness and the increase in neuroticism. Although according to the Big Five theory [7] personality dimensions are characterized by time and situational intra-individual stability, Robins et al. [20] found that neuroticism was negatively associated with age in a healthy population (18-22 age group). They found that, over a 4-year period, neuroticism decreased. Marsh et al. [21] also claim that neuroticism is negatively associated with age in a healthy population. Then, based on the comparison of our results and the results cited above, we can suppose that the opposite tendency is typical for women with MRKH syndrome. It is believed that personality can influence health in many different ways, e.g. through a connection with health behaviors or exposure and reactivity to stress $[22,23]$. Other cross-sectional studies also show that what makes ill and healthy women different is the level of the trait related to emotional adjustment (neuroticism), and only that, e.g. in the case of fibromyalgia [24], or rheumatoid arthritis and osteoarthritis [25]. This suggests that the differences observed may not be specific for a given disease but for ill women in general.

Analyses which took into account the time factor showed de facto that only women who have been aware of the diagnosis for a longer period of time, i.e. for more than 6 years, did indeed score higher in neuroticism than the female controls. It may suggest that this trait grew more intense over time. Furthermore, it must be mentioned that women with MRKH syndrome are usually diagnosed during adolescence and thus the awareness of the condition may have an impact on the devel- 
opment of personality traits and coping styles (cf. analysis of the relation between personality and health [22]). However, this hypothesis needs to be approached cautiously and verified by longitudinal studies. The result obtained is also in conflict with other studies according to which, 6 years after being diagnosed with infertility, women adapted themselves to the situation and experienced fewer symptoms of depression than women who had been ill for a shorter period [cf. 11]. The study however covered a wider range of causes of infertility, and the specificity of emotional consequences of MRKH syndrome diagnosis may be different.

Results concerning differences in coping skills between women with the syndrome and healthy women are compatible with results concerning personality traits. Women with MRKH syndrome scored higher in emotion-focused coping style and lower in problem-focused coping style. Since what prevailed among the respondents was the tendency to experience negative emotions, the women with the syndrome covered by the study also tended to focus on the negative affect (continuously experiencing, contemplating and thinking about negative emotions; see also the study on cancer patients [19]). However, it cannot be ruled out that the result obtained reflects only the contamination of items measuring neuroticism and emotion-focused coping style (both subscales contain statements related to the focus on the negative affect, mainly fear, which suggests that they may measure exactly the same thing). Nevertheless, a number of studies (using other research tools) show that infertile women focus to a large extent on the fact of not being able to have children and find it difficult to think about issues other than infertility, thus focusing on negative aspects $[12,26]$. It is difficult to find studies comparing coping styles in a group of chronically ill and healthy women. What we found in the databases of scientific publications was an article on coping styles in hypertensive patients [27]. The respondents included both men and women. They were characterized by an information-seeking style which produces acute or transient increases in subjective, behavioral, and physiologic arousal. However, in this group of patients this style is treated more as a contributing factor in either onset or exacerbation of the disorder. In our studies on women with MRKH syndrome resulting from a congenital defect, the coping style may not be treated as the cause of the illness but its consequence.

The fact of experiencing strong negative states is an obstacle to using the problem-focused coping style (strong negative affect makes it impossible to take direct problem-oriented action or create an action plan); therefore there were sig- nificant differences in this scope between women with MRKH and the female controls. The effect for the problem-focused coping style remained valid also after taking into account the length of time for which an individual has been aware of the diagnosis. Differences in the level of this coping style were de facto observed only between women who have known the diagnosis for more than 6 years and the group of healthy women. Thus it can be assumed that the predisposition to use the problem-focused coping style gets weaker as time passes and the tendency to focus on negative aspects persists or grows stronger. This hypothesis however also needs to be confirmed by longitudinal studies.

The cross-sectional character of the study has been reported as a limitation to the studies presented. Longitudinal analysis would make it possible to define possible changes in the scope of permanent features such as coping styles and neuroticism. MRKH syndrome is however a relatively rare congenital defect. It is estimated that approximately $0.2 \%$ of women suffer from this condition in Poland. The specificity of this condition makes it difficult to have a bigger group of respondents, and so far no longitudinal study has been conducted in this group.

Nevertheless, the results presented make it possible to define basic psychological and social problems related to MRKH syndrome, and to formulate proposals as regards psychological interventions addressed to this group of women. What seems to be of particular importance is the reformulation of the situation, changing the way it is perceived, focusing on resources available rather than on the element which is unachievable. The study results suggest that it is not the fact of not having children itself that has a negative impact on the psychophysical functioning but its perception as a key problem in one's life [28, 29]. This approach in psychotherapeutic interventions addressed to women with MRKH syndrome seems to be the most reasonable. What also seems to be important is the moment when psychotherapeutic interventions start. This study has shown that with time negative psychological consequences become more severe, and thus those women should be provided with specialist help from the moment the diagnosis is made. It may probably prevent the increase of neuroticism and the tendency to focus on negative emotions. It is also worth conducting longitudinal studies which would make it possible to evaluate the effectiveness of psychotherapeutic interventions and specialist support.

In conclusion, the specificity of psychological consequences of having MRKH syndrome is related to a higher level of neuroticism as compared to the general population, a stronger emotion-ori- 
ented coping style and a weaker task-oriented coping style. An important factor related to those variables is the time elapsed since the diagnosis. Women with MRKH syndrome should be provided with specialist psychological or psychiatric help from the moment they are diagnosed.

\section{Conflict of interest}

The authors declare no conflict of interest.

\section{References}

1. Fedele L, Bianchi S, Berlanda N. Laparoscopic creation of a neovagina and recovery of menstrual function in a patient with Rokitansky syndrome: a case report. Hum Reprod 2006; 21: 3287-9.

2. Panici PB, Bellati F, Boni T, Francescangeli F, Frati L, Marchese $C$. Vaginoplasty using autologous in vitro cultured vaginal tissue in a patient with Mayer von Rokitansky Kuster Hauser syndrome. Hum Reprod 2007; 22 2025-8.

3. Bidzan M. Psychological aspects of infertility. Oficyna Wydawnicza Impuls, Krakow 2006.

4. Bishop GD. Health psychology: itegrating mind and body. Wydawnictwo Astrum, Wrocław 2000.

5. Kubacka-Jasiecka D. Crisis intervention. Help in psychological crises. Wydawnictwa Akademickie i Profesjonalne, Warsaw 2010.

6. Wrześniewski K. Styles and strategies of coping with stress. Problems of measurement. In: The man in stressful situation. Theoretical and methodological problems. Heszen-Niejodek I, Ratajczak Z (eds). Publishing UŚ, Katowice 1996; 44-64.

7. Costa PT, McCrae RR. Four ways five factors are basic Pers Indiv Differ 1992; 13: 653-65.

8. Zawadzki B, Strelau J, Szczepaniak P, Śliwińska M. Personality Inventory NEO-FFI by Costa and McCrae: Polish adaptation. Manual. Pracownia Testów Psychologicznych PTP, Warsaw 2007.

9. Laggari V, Diareme S, Christogiorgos S, et al. Anxiety and depression in adolescents with polycystic ovary syndrome and Mayer-Rokitansky-Küster-Hauser syndrome. J Psychosom Obstet Gynaecol 2009; 2: 83-8.

10. Mohn C, Vassend O, Krogstad BS, Knardahl S. Personality traits and subjective health complaints in female TMD patients and healthy controls. Open Pain J 2010; 3: 134-43.

11. Cwikel J, Gidron Y, Sheiner E. Psychological interactions with infertility among women. Eur J Obstet Gynecol Reprod Biol 2004; 117: 126-31.

12. Jarmołowska A. Adoption of a child. Psychological analysis of decisions taken by men and women. Towarzystwo Naukowe KUL, Lublin 2007.

13. Munno D, Cappellin F, Macario PF, et al. Valutazione delle strategie di coping e dell'adattamento alia malattia in pazienti epilettici. Riv Psych 2008; 43: 220-7.

14. Brown MM, Brown AA, Jason LA. Illness duration and coping style in chronic fatigue syndrome. Psychol Rep 2010; 106: 383-93.

15. Oppelt P, Renner S, Kellermann A, et al. Clinical aspects of Mayer-Rokitansky-Küster-Hauser syndrome: recommendations for clinical diagnosis and staging. Hum Reprod 2006; 21: 792-7.

16. Costa PT, McCrae RR. Revised NEO Personality Inventory (NEO-PI-R) and NEO Five-Factor Inventory (NEO-FFI) pro- fessional manual. Odessa, FL: Psychological Assessment Resources 1992.

17. Endler NS, Parker JD. Multidimensional assessment of coping: a critical evaluation. J Pers Soc Psychol 1990; 58: 844-54.

18. Strelau J, Wrześniewski K, Jaworowska A, Szczepaniak P. Coping Inventory for Stressful Situations CISS. Manual. Pracownia Testów Psychologicznych PTP, Warsaw 2005.

19. Oniszczenko W, Laskowska A. Emotional reactivity, coping style and cancer trauma symptoms. Arch Med Sci 2014; 10: 110-6.

20. Robins RW, Fraley RC, Roberts BW, Trzesniewski KH. A longitudinal study of personality change in young adulthood. J Pers 2001; 69: 617-40.

21. Marsh HW, Ludtke O, Muthen B, et al. A new look at the big five factor structure trough exploratory structural equation modeling. Psychol Assesment 2010; 22: 471-91.

22. Ferguson E. Personality is of central concern to understand health: towards a theoretical model for health psychology. Health Psychol Rev 2013; 7: 32-70.

23. Bolger N, Zuckerman A. A framework for studying personality in the stress process. J Pers Soc Psychol 1995; 69: 890-902.

24. Malin K. Littlejohn GO. Neuroticism in young women with fibromyalgia links to key clinical features. Pain Res Treatment 2012; 2012: 1-7.

25. Smith BW, Zautra AJ. The role of personality in exposure and reactivity to interpersonal stress in relation to arthritis disease activity and negative affect in women. Health Psychol 2002; 21: 81-8.

26. Klimek R. Infertility curable or incurable. Państwowy Zakład Wydawnictw Lekarskich, Warsaw 1986.

27. Miller S, Leinbach A, Brody D. Coping style in hypertensive patients: nature and consequences. J Consult Clin Psych 1989; 57: 333-7.

28. Dąbrowska-Caban Z. Untypical marriages in Poland. Research reports. Probl Rodz 2001; 3: 32-40.

29. Kalus A. Couples childless by choice in the light of psychological literature. Probl Rodz 2001; 4: 15-9. 